\title{
Role of high dilutions in anesthetic recovery in dogs
}

Djair Teixeira Santos', Veronika Wittmann'1, Victoria Arrifano Moraes', Debora Koffke Alves $^{1}$, Kleber Peixoto da Cunha Junior1, Leoni Villano Bonamin ${ }^{1,2}$, Fabiana Rodrigues Santana' ${ }^{2}$, Daniele Di Marco', Cidéli de Paula Coelho ${ }^{1,2}$

${ }^{1}$ Santo Amaro University, São Paulo, Brazil

${ }^{2}$ Research Center of Paulista University, São Paulo, Brazil

Email: ccideli@uol.com.br

\begin{abstract}
Introduction: Post-operative period has been associated with risks like depression of cardiorespiratory system, hypothermia etc., especially under influence of anesthesia. Therefore, short anesthetic recovery in important.
\end{abstract}

Aims: The objective of this study was to evaluate whether homeopathic drug Papaver somniferum $30 \mathrm{cH}$ can help reducing the duration of post-surgery anesthesia, and whether there is any change in cardiac rhythm and body temperature.

Materials and Methods: We evaluated 16 dogs submitted for sterilization surgery in the Veterinary Hospital of University of Santo Amaro. The animals were divided in three groups: Group-I: treated with Papaver $30 \mathrm{cH}(\mathrm{n}=7)$; Group-II: treated with $10 \%$ hydroalcoholic solution $(n=5)$ (positive control); and Group-III: negative controls (who did not take anything)(n=4). Four drops of drug/placebo were given per os, immediately after the surgery, repeated every 15 min until dog became conscious. Data were analyzed statistically by ANOVA followed by the Tuckey Krammer Test, $\mathrm{p} \leq 0.05$ being significant.

Results: The results showed that animals treated with Papaver returned from anesthesia $(20 \pm 2.80$ minutes) faster than the hydroalcoholic group ( $34 \pm 6.49$ minutes), $p \leq 0.05$. No statistical difference was seen between the positive and negative control. There was no statistical difference between the groups in cardiorespiratory and temperature parameters.

Discussion: Other studies have shown similar effects using Veratrum album. The Papaver somniferum has remarkable pharmacological action in bradycardia, bradypnea, respiratory smooth muscle, with sedative and analgesic properties.

Conclusion: The Papaver somniferum 30cH may be considered as a medicinal aid in the shortening the post-surgical anesthesia time, however more studies are needed to establish this observation.

Keywords: Homeopathy, high dilutions, anesthesia, Papaver somniferum, dog.

(C) International Journal of High Dilution Research.

Not for commercial purposes.

\section{OPEN ACCESS}

Cite as: Santos DT, Wittmann V, Moraes VA, Alves DK, Cunha Junior KP, Bonamin LV, Santana FR, Marco DD, Coelho CP. High dilution use to support the anesthetic recovery in dogs. Proceedings of the XXIX GIRI Meeting; 2015 June 3 - 5;

Verona (Italy). Int J High Dilution Res. 2015; 14(2): 51-51 